\title{
Increases and fluctuations in nutrient availability do not promote dominance of alien plants in synthetic communities of common natives
}

\author{
Yanjie Liu ${ }^{1,2 *}$ Xiaoqi Zhang ${ }^{2 *} \quad$ Mark van Kleunen ${ }^{1,2}$
}

\author{
${ }^{1}$ Zhejiang Provincial Key Laboratory \\ of Plant Evolutionary Ecology and \\ Conservation, Taizhou University, Taizhou, \\ China \\ ${ }^{2}$ Ecology, Department of Biology, University \\ of Konstanz, Konstanz, Germany
}

\section{Correspondence}

Yanjie Liu

Email: yanjie.liu@uni-konstanz.de and

Mark van Kleunen

Email: mark.vankleunen@uni-konstanz.de

Funding information

China Scholarship Council

\begin{abstract}
1. It is frequently thought that global environmental changes, and especially the concomitant changes in environmental variability, could further increase the success of invasive species in native resident communities. However, very few studies explicitly tested this, and it remains unknown whether invasive and noninvasive alien species respond differently to resource fluctuations in resident communities.
\end{abstract}

2. We grew 10 invasive and 10 noninvasive species as target species in pot-mesocosms with four different synthetic native resident communities under six nutrient treatments differing in overall nutrient availability and temporal fluctuations in nutrient supply (constant low, constant high, gradual increasing, gradual decreasing, single large pulse, multiple smaller pulses). With the exception of plants in the constant low treatment, the plants were supplied the same total amount of nutrients during the experiment. We tested whether high-nutrient availability and fluctuations in nutrient supply increased performance of both invasive and noninvasive alien plants within native resident communities, and whether invasive ones benefited more than noninvasive ones.

3. We found that the increase in biomass in response to nutrient addition was stronger for invasive than for noninvasive alien species. However, as the native competitors benefited even more from nutrient addition, the relative biomass of the alien target-plant species, particularly the noninvasive ones, decreased. When the nutrient supply gradually increased, biomass of alien targets as well as native competitors decreased compared to the plants in the constant nutrient-supply treatment. Surprisingly, when nutrients were supplied as a single large pulse, the absolute and relative biomass of the alien target plants decreased. The reduction in relative biomass was even stronger for invasive than for noninvasive alien species, and a similar pattern was found when nutrients were supplied as multiple smaller pulses.

4. Our results confirm previous findings that invasive alien species benefit more from nutrient addition than noninvasive alien species. However, in contrast to 
previous findings, our results suggest that nutrient fluctuations can suppress biomass of alien plants relative to that of natives, at least when the natives are themselves very successful, common species.

\section{KEYWORDS}

biological invasions, environmental variability, exotic, global change, native community, non-native, plant-plant interactions

\section{1}

\section{INTRODUCTION}

With the increase in globalization and trade, a large number of plant species have been introduced to new regions where they are not native (Essl et al., 2011; Pyšek et al., 2017; van Kleunen et al., 2015; van Kleunen, Essl, et al., 2018). Some of these introduced alien species have established naturalized populations in the wild, and some of those have successfully spread and now occupy large areas in the introduced range. Such invasive species can reduce native species biodiversity and change ecosystem functions (Ricciardi, 2007; Vilà et al., 2011; Vitousek, D'Antonio, Loope, Rejmanek, \& Westbrooks, 1997) and might also have economic impacts (Pimentel, Zuniga, \& Morrison, 2005). The number of naturalized alien species is still increasing (Seebens et al., 2017), and invasions might further increase due to global change drivers (Haeuser, Dawson, \& van Kleunen, 2017; Liu et al., 2017; Seebens et al., 2015). Therefore, two major questions in ecology are why do some alien plant species become invasive and others do not, and how will the success of alien species be affected by global change drivers (Dawson, Fischer, \& van Kleunen, 2011; Dawson, Rohr, Kleunen, \& Fischer, 2012; Funk \& Vitousek, 2007; Haeuser et al., 2017; Jia, Dai, Li, \& Liu, 2016; Liu et al., 2017; van Kleunen, Weber, \& Fischer, 2010).

As a major component of global change, plant invasion is likely to be partly driven by and interact with other environmental changes (Bradley, Blumenthal, Wilcove, \& Ziska, 2010; Dukes \& Mooney, 1999). For example, a recent meta-analysis showed that invasive alien plants take more advantage of $\mathrm{CO}_{2}$ enrichment and climate warming than native species (Liu et al., 2017). On the other hand, many alien plant species that do not pose an invasion risk under current environmental conditions may become invasive under future conditions with ongoing global environmental change (Dullinger et al., 2017; Haeuser et al., 2017; Walther et al., 2009). Numerous empirical studies have tested how invasive plants interact with other environmental changes, but almost all of these studies considered only environmental changes in mean conditions (Leishman \& Thomson, 2005; Liu et al., 2017; Jia et al., 2016; Manea \& Leishman, 2015; but see Liu \& van Kleunen, 2017; Parepa, Fischer, \& Bossdorf, 2013). Environmental change, however, does not affect only the mean conditions but also environmental variability (Smith, 2011; Stenseth et al., 2002). Consequently, an improved understanding of how alien and native plants interact with changes in the temporal variability of resource supply can help to predict plant invasions.

The responses of plants to temporal variability in resource supply, compared to constant resource supply, might differ between alien and native species (Liu \& van Kleunen, 2017; Parepa et al., 2013). For example, Liu and van Kleunen (2017) grew individual plants from 29 alien and native species under one treatment with constantly low-nutrient availability and five treatments with high-nutrient availability that differed in the temporal supply of nutrients (constant high, increasing, decreasing, single large pulse, multiple smaller pulses). They found that compared to the constant high-nutrient supply, alien plants produced more biomass when nutrients were provided in a single large pulse in the middle of the growth period, whereas the reverse was true for the native plants (Liu \& van Kleunen, 2017). Such different responses to nutrient-supply variability between alien and native plants are likely to change the competitive balance. As a consequence, resource variability may promote invasion success of alien plants in resident communities (Davis, Grime, \& Thompson, 2000).

Indeed, a pot-mesocosm experiment by Parepa et al. (2013) supported the idea that resource variability may promote plant invasion. They grew the Japanese knotweed (Fallopia spp.) in an experimental community of native plants under five different scenarios of nutrient supply: constant low, constant high, increasing, single large pulse, multiple smaller pulses. They found that the invasive Japanese knotweed experienced a two- to fourfold proportional increase in above-ground biomass when nutrient supply varied over time, whereas a constant high application of nutrients did not result in a significant proportional increase in biomass of the invader (Parepa et al., 2013). However, this study was restricted to a single invasive species and a single experimental resident community. Therefore, similar studies on larger numbers of invader species and communities are required to test for general effects (van Kleunen, Dawson, Bossdorf, \& Fischer, 2014).

Building on the results of the studies by Parepa et al. (2013) and Liu and van Kleunen (2017), we carried out a multispecies experiment to test whether nutrient availability and fluctuations in nutrient supply promote invasion of invasive and noninvasive alien plants into resident native communities. As invasive alien plant species frequently capitalize more on additional resources than noninvasive alien plant species (Dawson, Fischer, \& van Kleunen, 2012; Dawson, Rohr, et al., 2012) and native species (Liu et al., 2017), we expect the invasive plants to take more advantage of an overall increase in nutrient availability than introduced noninvasive alien plants and native residents. Moreover, based on the findings of Parepa et al. (2013) and Liu and van Kleunen (2017), we expected that the invasive plants would benefit even more when the nutrient supply varies over time and particularly when the nutrients are supplied as a single large pulse or multiple smaller pulses rather than as a gradual increase or decrease. 
We used 10 pairs of taxonomically related invasive and noninvasive alien species (i.e., a total of 20 species) as target species. To assess whether the responses of the alien target species depends on the composition of the native communities, we used four different communities of three native grassland species. Single plants of the 20 alien target species were grown in mesocosm pots with each of these four native communities and exposed to six nutrient-supply treatments differing in the mean and temporal supply of nutrients (i.e., constant low, constant high, gradual increase, gradual decrease, a large single pulse, and multiple small pulses). By comparing the absolute above-ground biomass production of the alien target species as well as their biomass production relative to the biomass production of the native competitors in the different treatments (for a similar approach, see Parepa et al., 2013), we addressed the following specific questions: (a) Does an increase in mean nutrient availability promote absolute and relative biomass of both invasive and noninvasive alien plants? (b) Does variability in nutrient supply, particularly when nutrients are supplied in a single large pulse or in multiple small pulses rather than as a gradual increase or decrease, promote absolute and relative biomass of both invasive and noninvasive alien plants? (c) Do invasive alien plants take more advantage than noninvasive alien plants of increases in mean nutrient availability and fluctuations in nutrient supply?

\section{MATERIALS AND METHODS}

\subsection{Study species}

To investigate differences in plant responses to mean nutrient availability and temporal fluctuations in nutrient supply between invasive and noninvasive alien plants in the presence of native competitors, we chose 20 alien species (i.e., target species) and 12 native plant species (i.e., competitors; Supporting Information Table S1) from the herbaceous flora of Germany based on information in the BiolFlor database (www.ufz.de/biolflor). The 20 target species were chosen from nine families in such a way that they constituted 10 taxonomically related pairs of an invasive and a noninvasive alien plant. In other words, we avoided the status of the alien species being confounded by phylogeny (Felsenstein, 1985). Invasiveness has different dimensions, such as geographic range size, local abundance, habitat specificity, and spread rate (Catford et al., 2016; van Kleunen, Bossdorf, \& Dawson, 2018). As there are not sufficient data for most of these invasiveness dimensions, we used a measure of the geographic range size, which is also frequently positively correlated with local abundance of species (Gaston \& Lawton, 1990), to define invasiveness of the 20 target alien species in Germany. We assigned the alien species to the categories "invasive" and "noninvasive" based on the number of $130-\mathrm{km}^{2}$ grid cells occupied by the species in Germany (maximum 3,000) extracted from the FloraWeb database (www.floraweb.de). All invasive alien species occurred in more than 900 grid cells (median $=1,925$ ), and all noninvasive species occurred in fewer than 700 grid cells (median $=81$; Supporting Information Table
S1). Within each pair of species, the invasive species always occurred in at least four times more grid cells than the noninvasive species.

As plants with different life histories (i.e., annuals or perennials) might respond differently due to nutrient availability and variation therein due to differences in resource-allocation strategies (Roumet, Urcelay, \& Díaz, 2006), we assured that both groups of aliens included annuals and perennials (Supporting Information Table S1). In addition, because some alien species might not be invasive yet because they were introduced only recently, we chose species with a similar introduction history. Both the invasive and noninvasive alien target species have been introduced to Europe $>120$ years ago and do not differ in their minimum residence time (median: invasive $=199$ years and noninvasive $=174$ years; $\chi^{2}=0.036, p=0.850$, Kruskal-Wallis test; Supporting Information Table S1). All 12 native species, which included four forbs and eight grasses, occur frequently in German grasslands (Supporting Information Table S1). All seed materials were obtained from commercial seeds companies or the seed collection of the Botanical Garden of the University Konstanz (Supporting Information Table S1).

\subsection{Experimental set-up}

We conducted the experiment in a greenhouse of the Botanical Garden of the University of Konstanz, Germany (N: 4769'19.56", E: $9^{\circ} 17^{\prime} 78.42$ "). From 4 to 19 October 2016, we sowed the seeds of each species separately into trays $(12 \times 12 \times 4.5 \mathrm{~cm})$ filled with potting soil (Topferde ${ }^{\circledR}$; Einheitserde Co., Sinntal-Altengronau, Germany; pH 5.8; $2.0 \mathrm{~g} / \mathrm{L} \mathrm{KCl} ; 340 \mathrm{mg} / \mathrm{L} \mathrm{N} ; 380 \mathrm{mg} / \mathrm{L} \mathrm{P}_{2} \mathrm{O}_{6} ; 420 \mathrm{mg} / \mathrm{L} \mathrm{K}{ }_{2} \mathrm{O} ; 200 \mathrm{mg} / \mathrm{L}$ $\mathrm{S} ; 700 \mathrm{mg} / \mathrm{L} \mathrm{Mg}$ ). As species were known, from a previous pilot experiment, to germinate at different times, we sowed them on different dates (Supporting Information Table S1) to ensure that all species were in a similar developmental stage at the start of the experiment. On 25 October 2016, we selected similarly sized seedlings from each of the 20 alien and 12 native species and transplanted them into $2.5-\mathrm{L}$ circular plastic pots filled with a 1:1 mixture of sand and fine vermiculite. We chose the pot size such that the pots were large enough to avoid that most plants being pot bound by the end of the experiment, but small enough to ensure that the target plants would experience competition by the native community. In order to create four different native grassland communities, we randomly assigned the 12 native species into four different groups of three species (Supporting Information Table S1). We first transplanted two seedlings of each native-community member so that each pot included six individuals of native species growing at equal distance in a circle (diameter $=10 \mathrm{~cm}$ ) around the centre of the pot. The two individuals of the same species were planted at opposite ends of the circle (Figure 1). In total, we had 480 pots, with 120 pots for each of the four native communities. After planting the native competitors, we transplanted one seedling of an alien target species in the centre of each pot. For each of the 20 target species, we transplanted a total of 24 seedlings, which were equally divided over the four different native communities (i.e., six pots per native community). All pots were randomly assigned to positions on four greenhouse benches and were rerandomized again after five weeks. 
Species and replicates

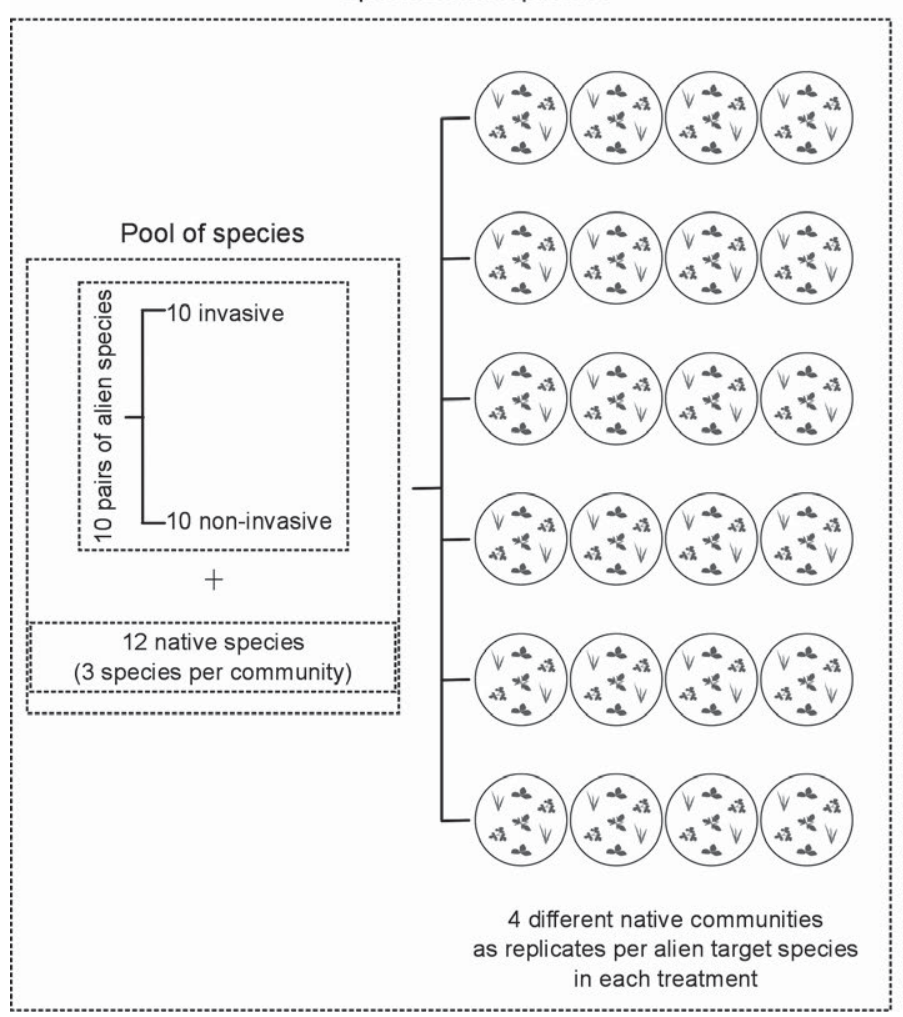

Nutrient treatment

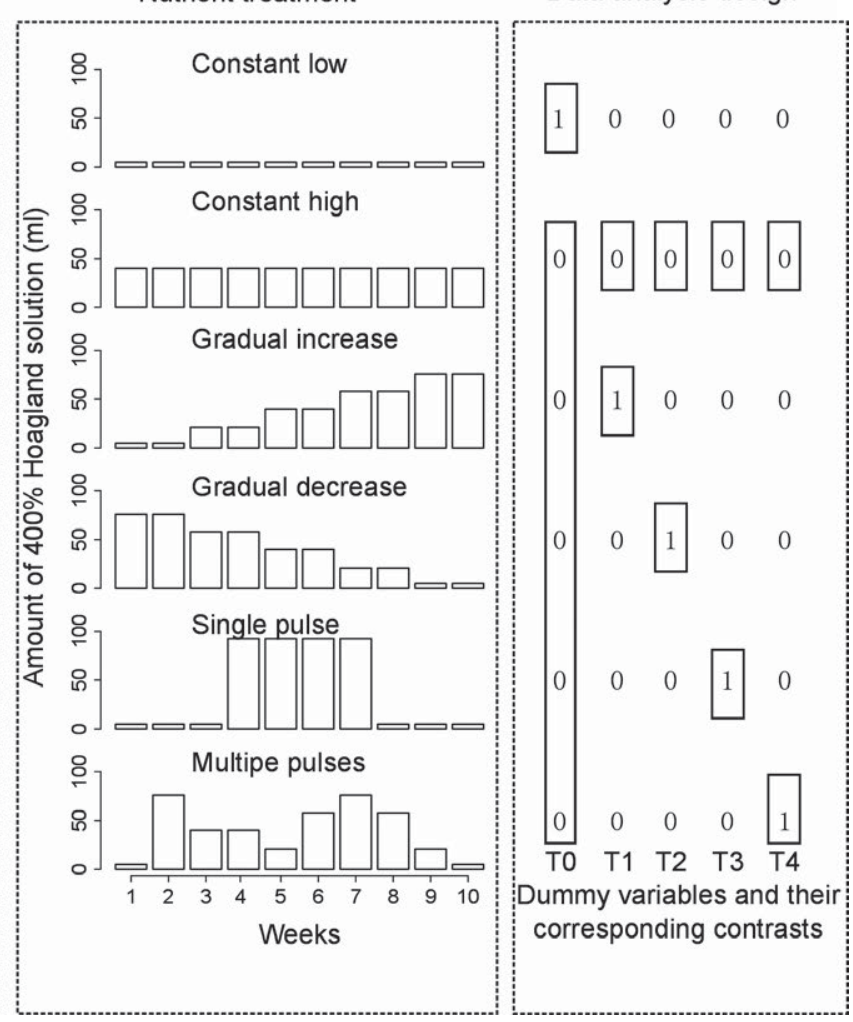

FIGURE 1 Graphical illustration of the experimental design (species, nutrient treatments, and replicates) and data-analysis design for the effects of the six nutrient treatments (i.e., coded as dummy variables to create specific contrasts for comparing treatment levels). Each bar in the box of nutrient treatment represents the amount of nutrient solution supplied each week during the 10 weeks of the experiment. The five high-nutrient level treatments (constant high, gradual increase, gradual decrease, single pulse, and multiple pulses) received the same total amount of nutrients during the 10 weeks, which was eight times higher than in the constant low-nutrient treatment. In the data-analysis design, dummy variables coding for the scenarios of nutrient supply were used to test the effects of the mean level of nutrient supply (constant low treatment vs. the average across the five high treatments; T0), and the effects of different temporal patterns of highnutrient supply vs. the constant high supply (T1-T4). For the latter, each contrast of interest was made by fitting the corresponding dummy variable after all other dummy variables (for details on model comparisons, see Liu \& van Kleunen, 2017). The two boxes around each dummy coding indicate the contrasts of interest

To avoid leakage of water and nutrient solution, which would create heterogeneity in water and nutrient availability within each treatment, we put a plastic dish under each pot. The temperature of the greenhouse was kept between $22^{\circ} \mathrm{C}$ and $28^{\circ} \mathrm{C}$, and additional lighting was provided to extend the daily light period to $16 \mathrm{hr}$.

One week after transplanting the seedlings, we started to apply the different nutrient-supply treatments at weekly intervals for a total of 10 weeks. As this study built on the results of a previous experiment testing the responses of individually grown rare and common aliens and natives to nutrient availability and fluctuations in nutrient supply (Liu \& van Kleunen, 2017), we used the same nutrient treatments as in that study. As it is difficult to compare the absolute nutrient levels in a pot experiment to those found in the field, we had chosen the low- and high-nutrient levels based on a pilot experiment showing that both levels were limiting plant growth (Liu \& van Kleunen, 2017), as is usually the case in nature. Having nutrient limitation in the high-nutrient treatment was also important because nutrient fluctuations might influence plant growth differently from a constant nutrient supply because of changes in the degree of nutrient limitation over time. We created the following six nutrient-supply patterns (Figure 1) using a Hoagland solution with all required macro- and micronutrients (Supporting Information Methods S1): (a) constant low, (b) constant high, (c) gradual increase, (d) gradual decrease, (e) single large pulse, and (f) multiple pulses of different magnitudes. Treatment (a) was the low-nutrient treatment, which received in total $50 \mathrm{ml}$ of a $400 \%$-strength Hoagland solution. Treatments (b) to (f) all received in total $400 \mathrm{ml}$ of a $400 \%$-strength Hoagland solution during the whole experiment, but differed in the temporal pattern of nutrient supply. There were four replicates per alien target species for each of the six nutrient treatments (one replicate per native community). We checked the pots every day, and when the soil in some pots started to look dry, we watered all plants by filling the dish under each pot to avoid water limitation.

\subsection{Harvest and measurements}

To be able to account for variation in initial size of alien target plants in the analyses, we counted the number of leaves (excluding the cotyledons) and measured the length and width of the largest leaf and 
the height of each alien target plant at the beginning of the experiment, immediately after transplanting. We calculated an estimate of initial leaf area per plant by multiplying the number of leaves and the length and width of the largest leaf. On 11 January 2017, 11 weeks after transplanting, we began to harvest the above-ground biomass for all pots one native community after the other. As the roots of the different species in each pot were intertwined, it was impossible to harvest the below-ground biomass. For each pot, we first harvested the alien target species and then harvested the three native competitor species. As 24 target plants died during the experiment, we only harvested 456 pots instead of 480 pots (Supporting Information Table S1). All biomass samples were dried at $70^{\circ} \mathrm{C}$ for $72 \mathrm{hr}$ and then weighed. We calculated total above-ground biomass per pot by summing the biomass of the alien target species and the three native competitors. We also calculated the biomass proportion of the alien target species in each pot by dividing the biomass of the alien target species by the total biomass (e.g., Parepa et al., 2013).

\subsection{Data analysis}

To test the effects of target-plant status (invasive vs. noninvasive alien) and nutrient treatments on above-ground biomass production of the alien target species, biomass proportion of the alien target species in each pot and total biomass per pot, we fitted linear mixed-effects models using the function Ime in the R package nlme (Pinheiro, Bates, DebRoy, \& Sarkar, 2016) in R 3.3.2 (R Core Team, 2016). To meet the assumptions of normality, biomass of the alien target species and total biomass per pot were natural-log-transformed, and biomass proportion of alien target species in each pot was square-root-transformed. We included alien target-plant status (invasive vs. noninvasive), average nutrient level (low vs. high), the different nutrient variability treatments nested within the high-nutrient level treatment (constant high vs. each of the nonconstant scenarios) and their interactions as fixed factors. To test the effects of the different nutrient treatments (i.e., nutrient levels [low vs. high], nutrient variability [constant high vs. each of the four nonconstant scenarios]), we created contrasts by coding the nutrient treatments as dummy variables (Schielzeth, 2010) T0 to T4 (Figure 1) in all models. Because initial plant-size variation might contribute to differences in final biomass of the target species, we included initial plant height and our estimate of initial leaf area as scaled natural-log-transformed covariates in the analysis of biomass production of the alien target species and biomass proportion of alien target species in each pot.

To account for phylogenetic nonindependence of species and for nonindependence of replicates of the same species, we included identity of the target species nested in family as random factors in all models. In addition to account for variation among the four different native communities, we also included native community as random factor in all models. As the homoscedasticity assumption was violated in all models, we also included variance structures to model different variances per species using the "varldent" function in the R package nlme (Pinheiro et al., 2016; see also Zuur, leno, Walker, Saveliev, \& Smith, 2009). We used log-likelihood ratio tests to assess significance of the fixed effects target-plant status, nutrient treatments (i.e., dummy variables TO to T4) and their interactions (Zuur et al., 2009; also see Liu \& van Kleunen, 2017). The log-likelihood ratio tests for fixed terms were based on comparisons of maximum-likelihood (ML) models with and without the terms of interest, and the variance components were estimated using the restricted maximum-likelihood method (REML) of the full model (Zuur et al., 2009).

\section{RESULTS}

Averaged across all six nutrient treatments, invasive and noninvasive alien species did not differ significantly in above-ground biomass production and biomass proportion in each pot (Table 1; Figure 2). The total biomass per pot, including the native species, was also not affected by status of the alien target species (Table 1; Figure 2). The marginal $R^{2}$ of the models ranged from 0.103 to 0.430 , and the conditional $R^{2}$ ranged from 0.484 to 0.895 (Table 1), indicating that both the fixed and random effects significantly contributed to the explanation of the variance.

\subsection{Biomass responses to an overall increase in nutrient availability}

Averaged across all 20 alien target species, an increase in the mean nutrient supply (averaged over the different temporal nutrient-supply patterns) significantly increased the above-ground biomass production of alien target species (+131.4\%; Table 1; Figure 2). This increase in biomass production was stronger for invasive alien species (+179.6\%) than for noninvasive alien species (+86.6\%; significant $\mathrm{S} \times \mathrm{TO}$ interaction in Table 1; Figure 2). However, as the total above-ground biomass production of each pot also increased in response to the mean nutrient supply (+144.0\%; Table 1; Figure 2), the biomass proportion of the alien target species in each pot decreased (-10.0\%; Table 1; Figure 2). This effect was caused by the noninvasive alien species only, as the biomass proportion strongly decreased for noninvasive alien species $(-19.9 \%)$ but not for invasive alien species (+0.4\%; significant S × T0 interaction in Table 1; Figure 2). The increase in total biomass production per pot in response to an increase in the mean nutrient supply was not significantly affected by status of the alien target plants (Table1; Figure 2). The results were very similar when we compared the constant low-nutrient treatment to the constant high-nutrient treatment only (Supporting Information Table S2).

\subsection{Biomass responses to temporal variability in nutrient supply}

In the high mean nutrient-supply treatments, when nutrients were gradually increased over time, biomass production of alien target species and total biomass per pot were significantly lower by $22.3 \%$ and $13.1 \%$, respectively, than when nutrients were supplied at a constant rate (significant T1 effects in Table 1; Figure 2). There were, however, no significant main effects for any of the biomass response variables when nutrients were gradually decreased over time instead of supplied at a constant rate (Table1). There were also no significant 


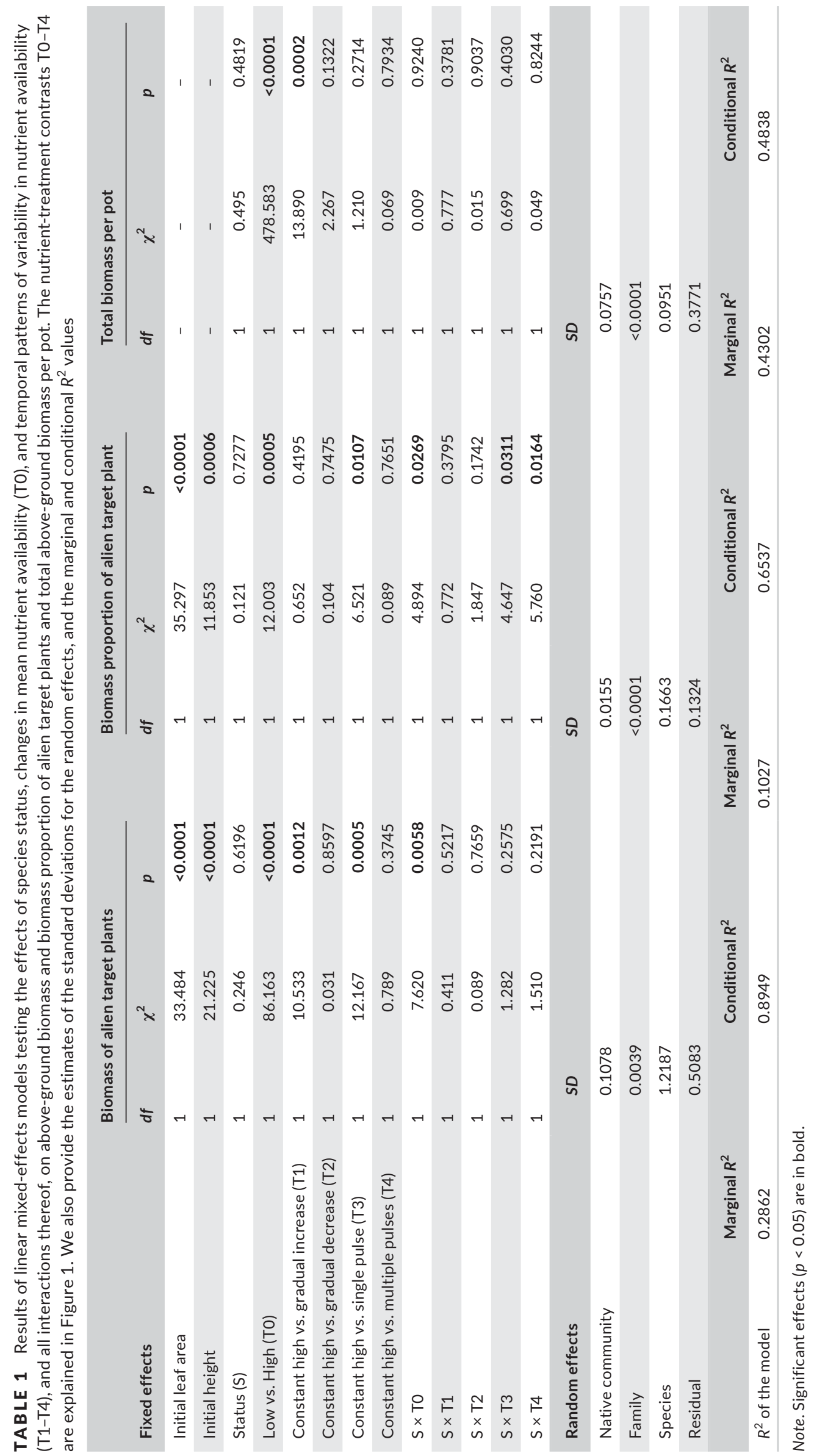



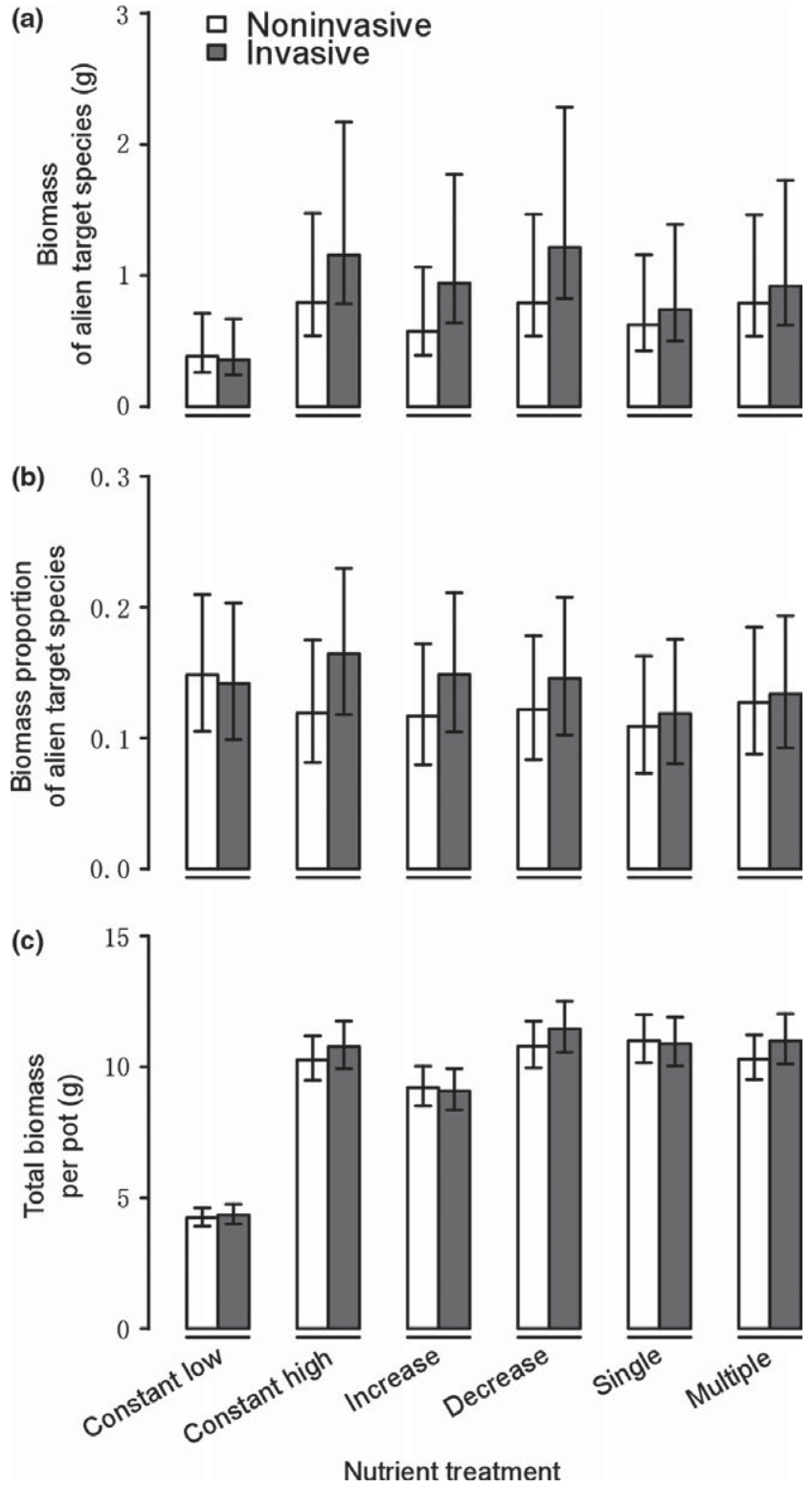

FIGURE 2 Modelled means of above-ground biomass production (a) and biomass proportion (b) averaged across the 10 invasive and the 10 noninvasive alien target species, and total biomass per pot (c) in the six nutrient treatments. Error bars represent standard errors

effects of interactions between plant status and any of the two types of gradual change in nutrient supply over time (Table 1 ).

When nutrients were supplied as a single large pulse in the middle of the 10-week growth period instead of at a constant high rate, biomass production of alien target species was significantly lower (-30.1\%; significant T3 in Table 1; Figure 2). The total biomass per pot, however, was not affected by whether the nutrients were supplied as a single large pulse or at a constant high rate (Table 1; Figure 2). Therefore, the biomass proportion of alien target species in each pot was significantly lower $(-19.8 \%)$ when nutrients were supplied as a single large pulse instead of at a constant high rate (significant T3 in Table 1; Figure 2). This decrease in biomass proportion was stronger for invasive alien species $(-27.9 \%)$ than for noninvasive alien species $(-8.6 \%$; significant $\mathrm{S} \times \mathrm{T} 3$ interaction in Table 1; Figure 2). On the other hand, there were no significant main effects for any of the biomass response variables when nutrients were supplied as multiple smaller pulses of different magnitudes instead of at a constant high rate (Table 1). However, when nutrients were supplied as multiple smaller pulses instead of at a constant high rate, the biomass proportion in each pot increased for noninvasive alien species $(+6.7 \%)$, whereas the reverse was the case for invasive alien species $(-18.8 \%$; significant $\mathrm{S} \times \mathrm{T} 4$ interaction in Table 1, Figure 2).

\section{DISCUSSION}

It has been suggested that invasive alien plant species might take more advantage of increased nutrient availability than noninvasive alien species (Dawson, Rohr, et al., 2012; Richards, Bossdorf, Muth, Gurevitch, \& Pigliucci, 2006). Our multispecies experiment corroborates this, as we found that the invasive alien plant species in our study benefited more of an increase in mean nutrient level than noninvasive alien plant species did. However, we also found that alien target-plant species, particularly the noninvasive ones, benefited proportionally less from the additional nutrients than the native competitors. In addition, the alien target species, particularly the invasive ones, decreased in biomass relative to the resident native competitors in response to nutrient pulses.

\subsection{Biomass responses to an overall increase in nutrient availability}

Comparison of traits between invasive and noninvasive alien species could provide insights into why some alien species become invasive and others fail to do so (van Kleunen, Dawson, Schlaepfer, Jeschke, $\&$ Fischer, 2010). Our study showed strong evidence that the difference between invasive and noninvasive species in response to an increase in the mean nutrient supply might be one of the mechanisms behind invasiveness of alien species. Richards et al. (2006) described different scenarios of how environmental responses (phenotypic plasticity) might differ between invasive and noninvasive species. Our results support their master-of-some scenario (Richards et al., 2006), in which the successful invader takes more advantage of favourable environments than less successful species. These results are consistent with the findings of many previous studies (Dawson, Rohr, et al., 2012; Leishman \& Thomson, 2005); however, surprisingly, the results contrast those of our previous study Liu and van Kleunen (2017), in which the biomass response to an increase in the mean nutrient level did not differ between invasive and noninvasive alien species. A potential reason for the discrepancy could be that Liu and van Kleunen (2017) used a partly different set of alien species. To test this, we re-analysed the data of the two studies for the subsets of species that were shared between them (five invasive and six noninvasive species; Supporting Information Table S3 and Figure 
S1). Although both studies showed the pattern that invasive alien species responded more strongly to nutrient addition than noninvasive alien species (Supporting Information Figure S1), this interaction effect was only significant in the current study (Table S3). Therefore, as the presence of neighbours may affect phenotypic responses (Callaway, Pennings, \& Richards, 2003), a more likely explanation for the inconsistency between the two studies is that in the current study invasive and noninvasive alien species were grown with native competitors, whereas Liu and van Kleunen (2017) grew them without competitors.

An increase in resource availability may promote plant invasions, because invasive alien species may be better at capitalizing on an increased availability of a limiting resource than species in the native communities (Funk, 2008; Leishman \& Thomson, 2005). Assessing the change in proportional biomass of an alien species in a native community may thus provide insight into whether the alien species might out-compete the native species or vice versa when the environment changes (Parepa et al., 2013; van Kleunen, Dawson, et al., 2010). We found that in response to increased nutrient availability, the total biomass per pot increased more strongly than the biomass of the alien target plants. This indicates that the native competitors benefit even more from nutrient addition than the alien species did. This was also reflected in the decrease in biomass proportion of the alien target species in response to nutrient addition. This effect was, however, fully accounted for by the decrease in biomass proportion of the noninvasive alien species, as the proportional biomass of the invasive alien species did not change in response to nutrient addition. Our findings therefore show that invasive alien plant species are not necessarily competitively superior to native plant species, but that noninvasive alien species are competitively inferior to native plant species.

The lack of evidence for a superior competitive ability of invasive species over native species after nutrient addition could reflect that the native species in our resident communities are also widespread (i.e., successful) in Germany (Supporting Information Table S1). Indeed, Dawson, Fischer, et al. (2012) found that common native species capitalized more on nutrient addition than rare native species, and Godoy, Valladares, and Castro-Díez (2011) found that invasive alien plant species in Spain showed similar responses to nutrient addition as widespread native species. Similarly, a previous meta-analysis revealed that invasive alien plants exhibited a higher performance than native plants overall, but that there was no significant difference between them when the analysis was limited to those native species known to be invasive elsewhere (i.e., which are also successful; van Kleunen, Weber, et al., 2010). It is indeed likely that many of the native species in our study are themselves invasive elsewhere as European species are over-represented in the global naturalized alien flora (van Kleunen et al., 2015). So, although invasive alien and common native species might both be master-of-some species (Richards et al., 2006) resulting in a competitive balance, we found evidence that noninvasive alien species are weak competitors in high-nutrient environments.
We assigned the alien species as invasive or noninvasive based on whether they are widespread in Germany or not. Although having a large geographic range does not per definition mean that an invasive species is also dominant in the local plant communities, geographic range size is usually positively correlated with local abundance of plant species (Brown, 1984; Gaston \& Lawton, 1990; Russell et al., 2005). Our finding that the biomass of the noninvasive (i.e., nonwidespread) but not the invasive alien species decreased relative to that of the native competitors at high-nutrient levels suggests that the noninvasive species will be less likely to establish or have a lower local abundance than the invasive alien species under high-nutrient conditions. This may indirectly affect the geographic range size of the alien species through effects of local abundance on seed production and thus dispersal (Crawley, 1997; Primack \& Miao, 1992). A low local abundance implies that the population is small and thus will have few individuals that can produce seeds that can be dispersed. Additionally, the lower numbers of flower and fruit visitors attracted by the small populations could also lead to a lower seed production (Ramírez-Rodríguez \& Amich, 2017) and seed dispersal (Schupp, Jordano, \& Gómez, 2010) per plant, respectively. The few seeds that will be dispersed are unlikely to colonize the new sites, particularly when the new sites are nutrient rich, due to the low competitive ability of the species. Therefore, the alien species that fail to capitalize more on an increase in mean resource availability than other alien species and native residents are not only likely to become nondominant but also less widespread.

\subsection{Biomass responses to temporal variability in nutrient supply}

Very few studies have assessed how the response of plants to nutrient addition depends on the temporal pattern of nutrient supply (Dener, Kacelnik, \& Shemesh, 2016; Liu \& van Kleunen, 2017; Parepa et al., 2013). We found that the biomass of the alien target plants and the total biomass per pot (also including the native competitors) were lower when the nutrient supply gradually increased than when the nutrient supply was kept constant. This is in line with the findings of Liu and van Kleunen (2017), and most likely reflects that in the gradual-increase scenario, the nutrient availability was insufficient at the early growth stage. However, our results contrast with the finding of Parepa et al. (2013) that biomass productions of their community did not differ between the scenario where plants grew under gradual increase in nutrient supply and a scenario of constant nutrient supply. A possible explanation for this discrepancy is that the experiment of Parepa et al. (2013) lasted longer than our experiment and that plants in the gradual-increase treatment of their study thus had more time to compensate for the initial nutrient limitation. In line with the findings of Liu and van Kleunen (2017), we also found no difference in plant performance between plants that were grown under gradually decreased nutrient supply and plants that were grown under constant nutrient supply. Possibly, nutrient availability might have decreased to a lesser 
extent than the nutrient supply because of storage of nutrients in the substrate and/or plant.

We found that in response to a single large nutrient pulse and in response to multiple small nutrient pulses, the biomass proportion of alien plant species decreased. This unexpected decrease was particularly the case for the invasive alien species; the noninvasive alien species even slightly benefited from multiple small nutrient pulses. This indicates that nutrient pulses may inhibit performance of invasive alien species relative to the performance of the native community. Although this is only a short-term experiment, the short-term benefit of nutrient pulses for native species may result in a priority effect (Fukami, 2015; Weidlich et al., 2017), resulting in a long-term advantage for native species. In our study, both the invasive alien target species and the native competitor species are very common species in Germany (Supporting Information Table S1). Both groups of common species may strongly capitalize on an increase in the mean nutrient availability, whereas the noninvasive alien species are likely to possess a resource-conservation strategy (Dawson, Fischer, et al., 2012; Richards et al., 2006). Possibly, such a strategy provided them with an advantage during the low-nutrient-supply periods in between the nutrient pulses. Consequently, the proportional biomass of noninvasive alien species may have been less affected by nutrient pulses than was the case for invasive species.

The results of our multispecies experiment are partly inconsistent with the predictions of the fluctuating-resource-availability hypothesis (Davis et al., 2000), which poses that a temporary excess in resources increases invasibility of a community. Other experiments found support for this hypothesis (Davis \& Pelsor, 2001; Liu \& van Kleunen, 2017; Parepa et al., 2013; Tognetti \& Chaneton, 2015). For example, Parepa et al. (2013) found that the biomass proportion of invasive Japanese knotweed (Fallopia spp.) in mesocosms with a native community significantly increased when plants received a single large nutrient pulse or multiple small nutrient pulses instead of a constant nutrient supply. Our findings also contradict the findings of our previous study (Liu \& van Kleunen, 2017), in which we found that alien species, and not native species, benefited from a large nutrient pulse when plants were grown without competition. Whatever the exact reason for these discrepancies, our results highlight that responses to nutrient-supply patterns for single plants might not be representative for plants grown under competition. Additionally, it also indicates that some native species can take even more advantage of a temporal increase in resource supply than invasive alien species.

\subsection{Caveats}

Although our study is the first multispecies comparative experiment that considers the effects of temporal nutrient-supply fluctuations on performance of invasive and noninvasive alien plants in competition with native residents, there are several caveats that should be considered in future studies. First, in nature nutrient availability is not only affected by the supply of nutrients but also by nutrient leaching, which was prevented in our study. Second, we only considered the effects of temporal variation in nutrient supply at a relatively high mean nutrient availability, and therefore, it remains unknown how temporal variation interacts with mean levels of nutrient supply. Third, due to the difficulty of separating roots in mix-cultures, we could only consider above-ground biomass in our study. Fourth, we cannot exclude the possibility that some plants might have been root bound and that this might have affected root allocation and biomass production of plants (Poorter, Bühler, Dusschoten, Climent, \& Postma, 2012; but see Supporting Information Discussion S1). These caveats should be considered when designing future experiments on the role of temporal fluctuations in resource supply on competition between plants.

\section{CONCLUSIONS}

Our results contribute to the growing amount of evidence that alien species able to strongly capitalize on an increase in the mean resource availability are likely to become widespread and invasive. However, although invasive alien species in our study capitalized more on additional nutrients than the noninvasive alien species, it did not give them an advantage over the native competitors, most likely because the latter are also widespread and thus successful. Surprisingly, however, we found that short temporal fluctuations in nutrient supply did not promote, but even suppressed biomass of the invasive species. In conclusion, although our study shows that the ability to capitalize on an increase in the average amount of nutrients is related to invasiveness of alien species, it also shows that it is not a general phenomenon that environmental variability promotes plant invasion.

\section{ACKNOWLEDGEMENTS}

We thank Beate Rüter, Claudia Martin, Otmar Ficht for help with experiment set-up and plant harvest. Y.L. thanks the China Scholarship Council (CSC) for financial support.

\section{AUTHORS' CONTRIBUTIONS}

Y.L. conceived the experiment. Y.L. and M.v.K. designed the experiment. X.Z. and Y.L. performed the experiment and collected the data. X.Z., Y.L., and M.v.K. performed data analyses and wrote the manuscript.

\section{ORCID}

Yanjie Liu (iD) http://orcid.org/0000-0003-3948-1246 


\section{REFERENCES}

Bradley, B. A., Blumenthal, D. M., Wilcove, D. S., \& Ziska, L. H. (2010). Predicting plant invasions in an era of global change. Trends in Ecology \& Evolution, 25, 310-318. https://doi.org/10.1016/j. tree.2009.12.003

Brown, J. H. (1984). On the relationship between abundance and distribution of species. The American Naturalist, 124, 255-279. https://doi. org $/ 10.1086 / 284267$

Callaway, R. M., Pennings, S. C., \& Richards, C. L. (2003). Phenotypic plasticity and interactions among plants. Ecology, 84, 1115-1128. https:// doi.org/10.1890/0012-9658(2003) 084[1115:PPAIAP]2.0.CO;2

Catford, J. A., Baumgartner, J. B., Vesk, P. A., White, M., Buckley, Y. M., \& McCarthy, M. A. (2016). Disentangling the four demographic dimensions of species invasiveness. Journal of Ecology, 104, 1745-1758. https://doi.org/10.1111/1365-2745.12627

Crawley, M. J. (1997). Plant ecology (2nd ed.). Cambridge, UK: Blackwell Sci. Ltd.

Davis, M. A., Grime, J. P., \& Thompson, K. (2000). Fluctuating resources in plant communities: A general theory of invasibility. Journal of Ecology, 88, 528-534. https://doi.org/10.1046/j.1365-2745.2000.00473.x

Davis, M. A., \& Pelsor, M. (2001). Experimental support for a resourcebased mechanistic model of invasibility. Ecology Letters, 4, 421-428. https://doi.org/10.1046/j.1461-0248.2001.00246.x

Dawson, W., Fischer, M., \& van Kleunen, M. (2011). The maximum relative growth rate of common UK plant species is positively associated with their global invasiveness. Global Ecology and Biogeography, 20, 299-306. https://doi.org/10.1111/j.1466-8238.2010.00599.x

Dawson, W., Fischer, M., \& van Kleunen, M. (2012). Common and rare plant species respond differently to fertilisation and competition, whether they are alien or native. Ecology Letters, 15, 873-880. https://doi.org/10.1111/j.1461-0248.2012.01811.x

Dawson, W., Rohr, R. P., van Kleunen, M., \& Fischer, M. (2012). Alien plant species with a wider global distribution are better able to capitalize on increased resource availability. New Phytologist, 194, 859867. https://doi.org/10.1111/j.1469-8137.2012.04104.x

Dener, E., Kacelnik, A., \& Shemesh, H. (2016). Pea Plants Show Risk Sensitivity. Current Biology, 26, 1763-1767. https://doi.org/10.1016/j. cub.2016.05.008

Dukes, J. S., \& Mooney, H. A. (1999). Does global change increase the success of biological invaders? Trends in Ecology \& Evolution, 14, $135-$ 139. https://doi.org/10.1016/S0169-5347(98)01554-7

Dullinger, I., Wessely, J., Bossdorf, O., Dawson, W., Essl, F., Gattringer, A., ... Dullinger, S. (2017). Climate change will increase the naturalization risk from garden plants in Europe. Global Ecology and Biogeography, 26, 43-53. https://doi.org/10.1111/geb.12512

Essl, F., Dullinger, S., Rabitsch, W., Hulme, P. E., Hulber, K., Jarosik, V., ... Pyšek, P. (2011). Socioeconomic legacy yields an invasion debt. Proceedings of the National Academy of Sciences of the United States of America, 108, 203-207. https://doi.org/10.1073/pnas.1011728108

Felsenstein, J. (1985). Phylogenies and the comparative method. American Naturalist, 125, 1-15. https://doi.org/10.1086/284325

Fukami, T. (2015). Historical contingency in community assembly: Integrating niches, species pools, and priority effects. Annual Review of Ecology, Evolution, and Systematics, 46, 1-23. https://doi. org/10.1146/annurev-ecolsys-110411-160340

Funk, J. L. (2008). Differences in plasticity between invasive and native plants from a low resource environment. Journal of Ecology, 96, 11621173. https://doi.org/10.1111/j.1365-2745.2008.01435.x

Funk, J. L., \& Vitousek, P. M. (2007). Resource-use efficiency and plant invasion in low-resource systems. Nature, 446, 1079-1081. https:// doi.org/10.1038/nature05719

Gaston, K. J., \& Lawton, J. H. (1990). Effects of scale and habitat on the relationship between regional distribution and local abundance. Oikos, 58, 329-335. https://doi.org/10.2307/3545224
Godoy, O., Valladares, F., \& Castro-Díez, P. (2011). Multispecies comparison reveals that invasive and native plants differ in their traits but not in their plasticity. Functional Ecology, 25, 1248-1259. https://doi. org/10.1111/j.1365-2435.2011.01886.x

Haeuser, E., Dawson, W., \& van Kleunen, M. (2017). The effects of climate warming and disturbance on the colonization potential of ornamental alien plant species. Journal of Ecology, 105, 1698-1708. https://doi.org/10.1111/1365-2745.12798

Jia, J., Dai, Z., Li, F., \& Liu, Y. (2016). How will global environmental changes affect the growth of alien plants? Frontiers in Plant Science, 7, 1623. https://doi.org/10.3389/fpls.2016.01623

Leishman, M. R., \& Thomson, V. P. (2005). Experimental evidence for the effects of additional water, nutrients and physical disturbance on invasive plants in low fertility Hawkesbury Sandstone soils, Sydney, Australia. Journal of Ecology, 93, 38-49. https://doi. org/10.1111/j.1365-2745.2004.00938.x

Liu, Y., Oduor, A. M. O., Zhang, Z., Manea, A., Tooth, I. M., Leishman, M. R., ... van Kleunen, M. (2017). Do invasive alien plants benefit more from global environmental change than native plants? Global Change Biology, 23, 3363-3370. https://doi.org/10.1111/j.1461-0248.2011.01628.x

Liu, Y., \& van Kleunen, M. (2017). Responses of common and rare aliens and natives to nutrient availability and fluctuations. Journal of Ecology, 105, 1111-1122. https://doi.org/10.1111/1365-2745.12733

Liu, Y., Zhang, X., van Kleunen, M., \& Cooke, J. (2018). Data from: Increases and fluctuations in nutrient availability do not promote dominance of alien plants in synthetic communities of common natives. Dryad Digital Repository, https://doi.org/10.5061/dryad.9jj4f50

Manea, A., \& Leishman, M. R. (2015). Competitive interactions between established grasses and woody plant seedlings under elevated $\mathrm{CO}_{2}$ levels are mediated by soil water availability. Oecologia, 177, 499506. https://doi.org/10.1007/s00442-014-3143-z

Parepa, M., Fischer, M., \& Bossdorf, O. (2013). Environmental variability promotes plant invasion. Nature Communications, 4, 1604. https:// doi.org/10.1038/ncomms2632

Pimentel, D., Zuniga, R., \& Morrison, D. (2005). Update on the environmental and economic costs associated with alien-invasive species in the United States. Ecological Economics, 52, 273-288. https://doi. org/10.1016/j.ecolecon.2004.10.002

Pinheiro, J., Bates, D., DebRoy, S., Sarkar, D. \& R Core Team (2016). nlme: linear and nonlinear mixed effects models. $R$ package version 3.1-128. Retrieved from https://CRAN.R-project.org/package=nlme

Poorter, H., Bühler, J., van Dusschoten, D., Climent, J., \& Postma, J. A. (2012). Pot size matters: A meta-analysis of the effects of rooting volume on plant growth. Functional Plant Biology, 39, 839-850. https://doi.org/10.1071/FP12049

Primack, R. B., \& Miao, S. L. (1992). Dispersal can limit local plant distribution. Conservation Biology, 6, 513-519. https://doi. org/10.1046/j.1523-1739.1992.06040513.x

Pyšek, P., Pergl, J., Essl, F., Lenzner, B., Dawson, W., Kreft, H., ... van Kleunen, M. (2017). Naturalized alien flora of the world: Species diversity, taxonomic and phylogenetic patterns, geographic distribution and global hotspots of plant invasion. Preslia, 89, 203-274. https://doi.org/10.23855/preslia.2017.203

R Core Team (2016). R: a language and environment for statistical computing. Vienna, Austria: R Foundation for Statistical Computing. Retrieved from https://www.R-project.org/

Ramírez-Rodríguez, R., \& Amich, F. (2017). Effects of local abundance on pollination and reproduction in Delphinium fissum subsp. sordidum (Ranunculaceae). Botany Letters, 164, 371-383. https://doi.org/10.10 80/23818107.2017.1383307

Ricciardi, A. (2007). Are modern biological invasions an unprecedented form of global change? Conservation Biology, 21, 329-336. https:// doi.org/10.1111/j.1523-1739.2006.00615.x

Richards, C. L., Bossdorf, O., Muth, N. Z., Gurevitch, J., \& Pigliucci, M. (2006). Jack of all trades, master of some? On the role of phenotypic 
plasticity in plant invasions. Ecology Letters, 9, 981-993. https://doi. org/10.1111/j.1461-0248.2006.00950.x

Roumet, C.,Urcelay, C., \& Díaz,S.(2006). Suites of root traits differ between annual and perennial species growing in the field. New Phytologist, 170, 357-368. https://doi.org/10.1111/j.1469-8137.2006.01667.x

Russell, L. K., Evans, S. J., Smith, L., Bevers, C. M., Luxford, A. P., Stubbs, W. J., \& Wilson, J. B. (2005). Distribution/abundance relations in a New Zealand grassland landscape. New Zealand Journal of Ecology, 29, 61-68.

Schielzeth, H. (2010). Simple means to improve the interpretability of regression coefficients. Methods in Ecology and Evolution, 1, 103-113. https://doi.org/10.1111/j.2041-210X.2010.00012.x

Schupp, E. W., Jordano, P., \& Gómez, J. M. (2010). Seed dispersal effectiveness revisited: A conceptual review. New Phytologist, 188, 333353. https://doi.org/10.1111/j.1469-8137.2010.03402.x

Seebens, H., Blackburn, T. M., Dyer, E. E., Genovesi, P., Hulme, P. E., Jeschke, J. M., ... Essl, F. (2017). No saturation in the accumulation of alien species worldwide. Nature Communications, 8, 14435. https:// doi.org/10.1038/ncomms14435

Seebens, H., Essl, F., Dawson, W., Fuentes, N., Moser, D., Pergl, J., ... Blasius, B. (2015). Global trade will accelerate plant invasions in emerging economies under climate change. Global Change Biology, 21, 4128-4140. https://doi.org/10.1111/gcb.13021

Smith, M. D. (2011). An ecological perspective on extreme climatic events: A synthetic definition and framework to guide future research. Journal of Ecology, 99, 656-663. https://doi. org/10.1111/j.1365-2745.2011.01798.x

Stenseth, N. C., Mysterud, A., Ottersen, G., Hurrell, J. W., Chan, K. S., \& Lima, M. (2002). Ecological effects of climate fluctuations. Science, 297, 1292-1296. https://doi.org/10.1126/science.1071281

Tognetti, P. M., \& Chaneton, E. J. (2015). Community disassembly and invasion of remnant native grasslands under fluctuating resource supply. Journal of Applied Ecology, 52, 119-128. https://doi. org/10.1111/1365-2664.12349

van Kleunen, M., Bossdorf, O., \& Dawson, W. (2018). The ecology and evolution of alien plants. Annual Review of Ecology, Evolution and Systematics, 49, 25-47. https://doi.org/10.1146/ annurev-ecolsys-110617-062654

van Kleunen, M., Dawson, W., Bossdorf, O., \& Fischer, M. (2014). The more the merrier: Multi-species experiments in ecology. Basic and Applied Ecology, 15, 1-9. https://doi.org/10.1016/j. baae.2013.10.006

van Kleunen, M., Dawson, W., Essl, F., Pergl, J., Winter, M., Weber, E., ... Pyšek, P. (2015). Global exchange and accumulation of non-native plants. Nature, 525, 100-103. https://doi.org/10.1038/nature14910

van Kleunen, M., Dawson, W., Schlaepfer, D., Jeschke, J. M., \& Fischer, M. (2010). Are invaders different? A conceptual framework of comparative approaches for assessing determinants of invasiveness. Ecology Letters, 13, 947-958. https://doi.org/10.1111/j.1461-0248.2010.01503.x

van Kleunen, M., Essl, F., Pergl, J., Brundu, G., Carboni, M., Dullinger, S., ... Dehnen-Schmutz, K. (2018). The changing role of ornamental horticulture in alien plant invasions. Biological Reviews, 93(3), 1421-1437. https://doi.org/10.1111/brv.12402

van Kleunen, M., Weber, E., \& Fischer, M. (2010). A meta-analysis of trait differences between invasive and non-invasive plant species. Ecology Letters, 13, 235-245. https://doi. org/10.1111/j.1461-0248.2009.01418.x

Vilà, M., Espinar, J. L., Hejda, M., Hulme, P. E., Jarosik, V., Maron, J. L., ... Pyšek, P. (2011). Ecological impacts of invasive alien plants: A meta-analysis of their effects on species, communities and ecosystems. Ecology Letters, 14, 702-708. https://doi. org/10.1111/j.1461-0248.2011.01628.x

Vitousek, P. M., D'Antonio, C. M., Loope, L. L., Rejmanek, M., \& Westbrooks, R. (1997). Introduced species: A significant component of human-caused global change. New Zealand Journal of Ecology, 21, 1-16

Walther, G. R., Roques, A., Hulme, P. E., Sykes, M. T., Pyšek, P., Kuhn, I., ... Settele, J. (2009). Alien species in a warmer world: Risks and opportunities. Trends in Ecology \& Evolution, 24, 686-693. https://doi. org/10.1016/j.tree.2009.06.008

Weidlich, E. W. A., von Gillhaussen, P., Max, J. F. J., Delory, B. M., Jablonowski, N. D., Rascher, U., \& Temperton, V. M. (2017). Priority effects caused by plant order of arrival affect below-ground productivity. Journal of Ecology, 106(2), 774-780. https://doi. org/10.1111/1365-2745.12829

Zuur, A., leno, E., Walker, N., Saveliev, A., \& Smith, G. (2009). Mixed effects models and extensions in ecology with R. New York, NY: Springer. 